\title{
1-P-061 Poster Sessions
}

\section{Protective effect of nitric oxide on QOL and mucosal injury induced by a constitutive administration of methotrexate to rats.}

\author{
Saki Shiga ${ }^{1}$, Takuji Machida ${ }^{1}$, Takumi Yanada ${ }^{1}$, Maiko Machida $^{2}$, Ashiko Hirafuji $^{1}$, Kenji lizuka $^{1}$

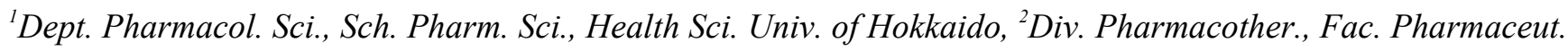 \\ Sci., Hokkaido Univ. Sci.
}

The role of nitric oxide (NO) on quality of life (QOL) and mucosal injury induced by a single and a consecutive administration of methotrexate was investigated. Rats received methotrexate intraperitoneally either a single administration $(50 \mathrm{mg} / \mathrm{kg})$ or a consecutive administration $(12.5 \mathrm{mg} / \mathrm{kg} /$ day $)$ for 4 days. $\mathrm{N}^{\mathrm{G}}$-nitro-L-arginine methyl ester (L-NAME) was given subcutaneously to inhibit NO synthase (NOS). $96 \mathrm{~h}$ after a first administration of methotrexate, ileal tissues were collected to analyze. Both a single administration and a consecutive administration of methotrexate decreased the QOL. When methotrexate was administered consecutively, L-NAME further worsened the QOL. A consecutive, but not a single, administration of methotrexate caused a significant mucosal injury and inflammation. A consecutive, but not a single, administration of methotrexate significantly induced a constitutive NOS expression in the ileal tissue. The role of NO derived from constitutive NOS in the reduction of QOL and small intestinal by methotrexate administration may be more important in a consecutive administration than a single administration. 